\title{
Statistical evaluation of the flight activity of the European grapevine moth (Lobesia botrana Den. \& Schiff.) in the Northeastern Black Sea Region (Russia)
}

\author{
Oleg Orlov*, and Evgeniya Yurchenko
}

Federal State Budgetary Scientific Institution North Caucasian Federal Scientific Horticulture and Viticulture Center (FSBSI NCFSHVC), 350901, 39, 40-Letiya Pobedy, str., Krasnodar, Russian Federation

\begin{abstract}
The paper presents a statistical assessment of the probabilistic nature of summer in males of Lobesia botrana Den. et Schiff. according to the data of pheromone monitoring in the vineyards of the North-Eastern Black Sea region. The observed and calculated basic statistical indicators of the frequency binomial distribution of summer (beginning, length of summer, the central trend of summer and the expected period of the central trend) of three economically significant generations are considered. With significant restrictions, the period of mass summer of the pest is indicated, calculated as the standard deviation of summer of all individuals in the period. Indicators such as kurtosis, asymmetry and others have been calculated and analyzed, which make it possible to understand better the nature of the summer of a harmful object. When analyzing the dynamics of the fly of the Lobesia botrana Den. et Schiff by various methods, it is concluded that the actually observed fly of the pest are more uniform in comparison with theoretical abstraction. Wherein, the first fly is more extended and unstable than the subsequent periods of mating - this character of fly is influenced by abiotic environmental conditions. Based on long-term monitoring data of seasonal cycles of development, which include four generations, the period of full development of one generation of the Lobesia botrana Den. et Schiff in field conditions was established. Its main probabilistic indicators and differences between generations are provided. These data can help in understanding the age dynamics of the grape leafroller population and its probabilistic nature in order to improve the prognosis of the pest development and the timing of protective measures.
\end{abstract}

\section{Introduction}

The Lobesia botrana Den. Et Schiff. is a Mediterranean species expanding its range in the regions of industrial viticulture. Currently, it has occupied all the countries of the Mediterranean, the countries of the Near and Middle East, the countries of Central Asia

\footnotetext{
* Corresponding author: orlovov@mail.ru
} 
(https://gd.eppo.int/taxon/POLYBO/distribution)[1]. The pest spread along the eastern coast of Africa to Kenya [2,3], occupied a new habitat for itself in South America - the wine-growing regions of Chile and Argentina [4]. Also from 2009 to 2014, it was found in various regions of California in North America [5], but thanks to the work of the local quarantine service, the invader was successfully destroyed [6].

This dominant grape phytophage has been a typical harmful object for more than half a century, since the end of the 60s of the last century, and has economic importance in the vineyards of the North-Eastern Black Sea region. Developing in four generations, it damages the generative organs - inflorescences and clusters. Its harmful stages are caterpillars of all ages. The greatest harm is caused to ripening grapes due to development of rot on damaged berries. With a high number of pests, you can lose up to $75-80 \%$ of the crop.

Effective insecticidal control of the Lobesia botrana Den. Et Schiff. shall be based on knowledge of the phenology of the pest, since the most vulnerable stages in the life cycle are the phases of the larvae of the first instars, when the insect is most sensitive to the insecticide. Identifying and analyzing the dynamics of the number of recently hatched caterpillars directly in the field can be challenging. Monitoring the dynamics of the summer of males for pheromone (pheromone monitoring) allows to cope with it, and also makes it possible to prepare in advance for treatments by planning them in the system of protective measures. Therefore, detection of the peak or peaks of summer of the pest by generations in each specific case is technologically important to protect the crop.

The dynamics of summer, the appearance and activity of a particular individual of the Lobesia botrana Den. Et Schiff. in the field is influenced by many factors, hence the process of the summer period itself can be considered stochastically. Appearance of representatives of a population can be described in terms of a probability distribution on a calendar scale. The distribution factor is the time from the beginning of summer. The daily number of freshly caught individuals per pheromone trap characterizes the frequency of the variation series. Although the summer graph has high frequency fluctuations by day, the combination of the nearest summer days, i.e. a decrease in the groups of the variation series, brings the form of the histogram to normal.

The aim of the study was to describe the fly of the Lobesia botrana Den. Et Schiff. in ampelocenoses of the Taman Peninsula using standard statistical indicators of the frequency binomial distribution.

\section{Methods}

The object of the study was the male grape roll, captured by pheromone traps (the main component of the pheromone is (E, Z) 7.9 Dodecadienyl acetate). The data of summer monitoring of the Lobesia botrana Den. Et Schiff. were collected in the industrial plantations of the largest wine-growing holding of the Russian Federation, JSC Agrofirm Yuzhnaya (Taman Peninsula, Taman subzone of viticulture). Pheromone monitoring was carried out regularly from April to October annually from 2013 to 2019 inclusively, on severely damaged Western European grape varieties (V. vinifera convar. occidentalis Negr. subconvar . gallica Nem.).

In our calculations, we used all four periods of summer (overwintered generation, first, second, and third generations of the current season). Statistical indicators were calculated for the first three periods of summer in the annual cycle of the pest. All four periods were used to calculate the indicators of the development period of one generation.

The summer indices ofLobesia botrana Den. Et Schiff. were calculated using standard statistical methods [7, 8] used in population biology and in the experimental work of agricultural crop production $[9,10]$. Annual summer data were decomposed as time series 
in Excel tables for each period separately. The table of variation series was constructed in such a way that it began from the first observed day of summer of the pest. Therefore, every day of summer in the calendar, starting from the first observed day of summer, corresponds to the sequential number of the variation series. The length of summer corresponds to the size of the variation series.

For each variation series, the central tendencies were calculated and the arithmetic mean for each generation were calculated from them. These values indicate when half of all hatched individuals are noted (equator). The obtained central tendencies were used to calculate the error of the sample mean. It is, in fact, a standard deviation and shows when it is probabilistically possible to observe the central summer trend of a pest of a certain period.

The calculation of the main deviations of the variation series (standard deviation) of summer for all individuals of each period and its arithmetic mean was carried out by standard statistical methods using variation series [11]. The calculation of the error of the sample mean was carried out according to the values of the standard deviations.

The kurtosis, asymmetry and coefficient of variation were calculated using standard statistical methods for all generations and for a group from all periods of summer. Since the asymmetries across the summer periods showed significant differences and were not normally distributed, the coefficient of variation was calculated as a quotient of the standard deviation for the half of the summer period, and not for its central trend.

The period of development of one generation of the Lobesia botrana Den. Et Schiff. was calculated as the arithmetic mean of the difference in the central tendencies in the sequential cycle of generations of the season. Its standard deviation is calculated. The arithmetic mean over the generations was also calculated, the statistical significance was assessed by the Student's criterion.

Calculations were carried out in Excel and Past4.03 tables [12, 13]

Statistical terms used in the paper:

- Asymmetry characterizes the displacement of the distribution relative to the central trend.

- The normal distribution is a probability distribution shaped like a symmetrical bell; its parameters are the central tendency and standard deviation (square root of variance).

- The sample mean error is the standard deviation calculated from the central tendencies of all samples included in these calculations.

- The standard deviation is one of the ways to estimate the dispersion of data, indicating the degree of deviation of observations from the central trend. The greater the deviation, the greater the alterability, variability of observations.

- The central trend is the arithmetic mean of the distribution of the observed sample variability values.

- Kurtosis characterizes the sharpness (positive value) or flatness (negative value) of the distribution compared to the normal curve.

\section{Results}

Seven-year (2013-2019) field monitoring of the dynamics of the abundance of the Lobesia botrana Den. Et Schiff. using pheromone traps made it possible to establish the average length of the first summer of the pest in the conditions of the region, which was 42 days. The longest years recorded by us for this period are marked as 53 days, the shortest 32 days. The average period of the second summer is set at 28 days. For the third summer, the average length is not presented due to the instability of its character - large fluctuations in the periods of summer, and in some years its complete lack of expression. 
The statistical indicators of the summer of the Lobesia botrana Den. Et Schiff. are provided in Table 1, the arithmetic mean values of the central tendencies by generations are indicated, i.e. when half of all individuals of the pest fly out (equator), as well as the error of the sample mean.

Table. The main indicators of the frequency distribution of the summer of the Lobesia botrana Den. Et Schiff., Taman Peninsula, 2013-2019.

\begin{tabular}{|c|l|c|c|c|}
\hline \multirow{2}{*}{ Years } & \multicolumn{2}{|c|}{ Central trend } & \multicolumn{2}{c|}{$\begin{array}{c}\text { Summer standard deviation of all } \\
\text { individuals }\end{array}$} \\
\cline { 2 - 5 } & $\begin{array}{c}\text { Arithmetic } \\
\text { mean, date }\end{array}$ & $\begin{array}{c}\text { Sample mean } \\
\text { error, days }\end{array}$ & $\begin{array}{c}\text { Arithmetic mean, } \\
\text { days }\end{array}$ & $\begin{array}{c}\text { Sample mean } \\
\text { error, days }\end{array}$ \\
\hline I & May 11 & 5.7 & 8.5 & 1.6 \\
\hline II & June 30 & 3.3 & 5.7 & 1.9 \\
\hline III & August 12 & 4.6 & 5.7 & 1.6 \\
\hline
\end{tabular}

According to the laws of normal distribution, in $68 \%$ of cases the probability of observing the middle of summer or the central trend of summer is within 2 standard deviations or sample errors [11]. For overwintered individuals, this fluctuation occurs within a fairly wide range - 11 days. The period when the average value can be observed with a probability of $95 \%$ (4-fold value of the sample mean error) - the central trend fluctuates within quite impressive limits (23 days).

Probabilistic fluctuations in the central tendencies of subsequent years - the first and second generations are no longer so significant. With a probability of $68 \%$ or 2 standard deviations, the central tendencies are within 6-7 and 11 days for the second and third summer, respectively. With a probability of $95 \%$, this is the value of 13 and 18 days, respectively.

The partial error of the sample mean to the arithmetic mean of the length of this summer overwintered individuals is 7.5 , and the summer of the second generation is 8.5 . The period when the annual central trend can be expected turned out to be longer for the first summer. I.e. the relative value of the period of fluctuations of the central tendency for the first summer of the Lobesia botrana Den. Et Schiff. is greater than for the second summer.

The average kurtosis value of all summer periods is -0.25 , its fluctuations are expressed in rather wide limits, and the distribution histogram is "far" from the normal distribution (Figure). No significant differences were found in the values of kurtosis for generations.

The average value of the asymmetry of all periods of summer is close to zero -0.05 . Fluctuations of asymmetry, as well as fluctuations of kurtosis, are expressed in wide limits, the distribution histogram has a normal form (Figure 1). The share of summer periods with significant asymmetry (exceeding 0.5 in modulus) is $37 \%$. It can be stated that their arithmetic means have differences $(-0.17 ; 0.10$ and 0.20 for three periods, respectively), despite the fact that the assessment by the Student's criterion did not show significant differences between the asymmetries of different summer periods (since there are significant fluctuations). The kurtosis calculated from the values of the asymmetry of different periods of summer, has a strong negative value for the first period -1.13 and strong positive values for the second and third summers - 0.6 and 0.85 , respectively. The arithmetic mean central tendency is in the second half of the first summer period, while the opposite tendency is observed in subsequent generations. 

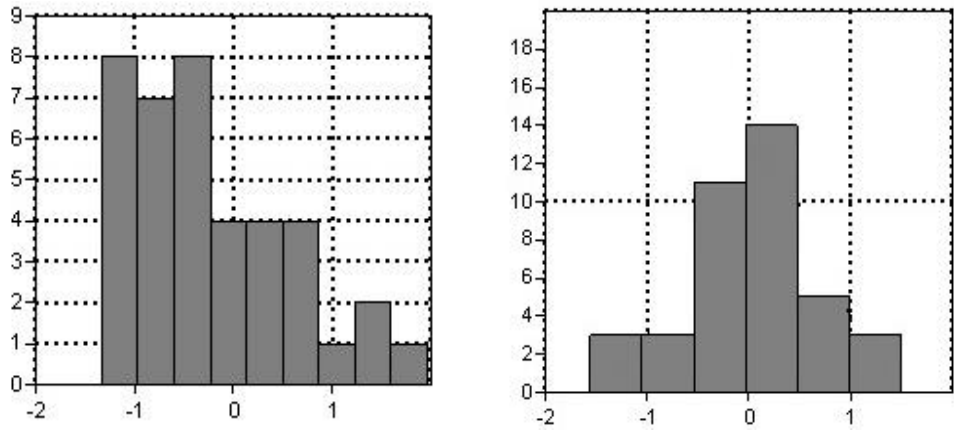

Fig. Histogram of the distribution of kurtosis (left) and asymmetry (right) values of various generations of the Lobesia botrana Den. Et Schiff. in vineyards in the Taman Peninsula (North-Eastern Black Sea region), 2013-2019.

The coefficient of variation has no pronounced differences between generations, has an average value of 0.41 , and its standard deviation is 0.11 .

In addition, to understand the nature of the summer of the pest, it is very important to predict the departure of the bulk of butterflies (massive years). In statistics, with a normal distribution of the sample, this question is answered by the standard deviation (Table). Expected fly of $68 \%$ and $95 \%$ are observed within 2 and 4 standard deviations, respectively [11]. It shall be noted that these values are average and have their own sample mean error, but it is small and is within one or two days. Therefore, most likely, the bulk of the pest for the first period of summer can be expected in more than 17 and 34 days $(68 \%$ of individuals and $95 \%$ of individuals, respectively). For the next two periods - more than 11 and 23 days.

The periods of development of one generation varied within wide limits. The average period of development of a generation is 45.1 days, the standard deviation is 4.9 days. We can say that development period cannot take less than 30 days and more than 60 days (3fold standard deviation in both directions from the average development period). The excess is equal to 0.53 , which means that the period of development of one generation is much more likely to fall on the average than according to the predicted values of the standard deviation. The obtained values of the root-mean-square deviation and significant positive kurtosis allow us to conclude that in more than $68 \%$ of cases, the full development of one generation of the Lobesia botrana Den. Et Schiff. in the field under the influence of all types of factors is completed in 40-50 days.

The average development of the first two generations is 44 and 48 days, respectively, their values have significant differences $(\mathrm{P}<0.05)$. Wherein, the third generation develops faster than the first two ones -39 days. The differences between the means of the first two and the third ones are significant $(\mathrm{P}<0.01)$.

\section{Discussion}

Long-term monitoring of the seasonal years of the Lobesia botrana Den. Et Schiff. has shown that the first fly is always much longer than the subsequent ones and averages 42 days, while the average period of the second fly is 27 days. The third fly is long enough, but not stable up to its complete lack of expression. Such a length of the first summer of the pest, in comparison with the subsequent one, is most likely associated with the uneven influence of weather factors of the environment at the stage of development of the Lobesia botrana Den. Et Schiff. (as a poikilothermic animal) during the period of hibernation and emergence from it. The evidence confirming the effect of lower temperatures on the 
duration of the first summer is its more elongated beginning. This is reflected in the fact that its average asymmetry has negative values, while the fly of subsequent generations have positive values.

The calculated share of error in the sample mean in the first year (7.5) turned out to be higher than the same indicator in the second year (8.5). This indicates the regularly unstable nature of the summer of overwintered individuals in comparison with subsequent periods of summer and may indicate differences in the conditions of overwintering.

The high coefficient of variation (0.41) and negative kurtosis $(-0.25)$ show that the actually expected number of males of Lobesia botrana Den. Et Schiff. that flies out exceeds the values of the theoretical model inherent in the normal distribution. The real observed fly of the Lobesia botrana Den. Et Schiff. are more stretched and more uniform . Probably, its bulk, for the first period, can be expected in more than 17 and 34 days (68\% of individuals and $95 \%$ of individuals, respectively). For the next two periods - more than 11 and 23 days ( $68 \%$ of individuals and $95 \%$ of individuals, respectively).

High fluctuations in the asymmetry of the distribution of male pests over the fly period ( $37 \%$ of observations exceed the value of 0.5 ), as well as the kurtosis values distributed "abnormally", indicate that the statistically described years is a theoretical generalization that does not exclude the need for each specific case tracking during field phytosanitary monitoring of the dynamics of the fly of the pest.

According to our calculations, based on the obtained data of the standard deviation and kurtosis (having positive values), with a high degree of probability, the period of development of one generation of the Lobesia botrana Den. Et Schiff. lasts 40-50 days (with an average value of 45 days) and does not go beyond 30-60 days. The rate of development of generations increases in the cycle of generations, from the first to the next, and the autumn, third generation develops in the region of 40 days.

\section{Conclusion}

The paper presents the observed in the field and calculated statistical indicators of the dynamics of the frequency binomial distribution of the summer of the Lobesia botrana Den. Et Schiff. of three economically significant periods: the beginning, the length of fly, the central trend of fly and the expected period of the central trend. Additionally, with significant restrictions, the period of mass fly is indicated. The actually observed years of the Lobesia botrana Den. Et Schiff. are more stretched and more uniform than with the theoretical normal distribution. Wherein, the first years are more extended and unstable, compared with the subsequent periods of mating, which is associated with the influence of abiotic environmental factors. The period of full development of one generation of the Lobesia botrana Den. Et Schiff. was established in the field. The main probabilistic indicators of development and their differences between generations are presented. These data can help in understanding the age dynamics of the grape leafroller population and its probabilistic nature in order to improve the prognosis of the pest development and the timing of protective measures.

\section{References}

1. A. P. Gutierrez, L. Ponti, G. Gilioli, J. Baumgärtner, Agric. For. Entomol., 20, 255 (2018)

2. F. Bounaceur, H. Mostefaoui, M. Abdelli, F. Z. Bissaad, 1, 9 (2011)

3. P. Le, Agricultural insects of East Africa (1959)

4. G. Heit, W. Sione, P. Cortese, J. Crop Prot. 4, 605 (2015) 
5. T.M. Gilligan, M.E. Epstein, S.C. Passoa, Proc. Ent. Soc. Wash., 113, 1 (2011)

6. APHIS Declares Eradication of European Grapevine Moth (Lobesia botrana) and Eliminates All Quarantine Areas in California (National Policy Manager, 2016)

7. L. J. Cardinal, J. Community Hosp. Intern. Med. Perspect., 5 (2015)

8. K.A. Gomez, A.A. Gomez, Statistical procedures for agricultural research (1983)

9. V. V. Brygadyrenko, D. Y. Reshetniak, Folia Oecologica, 41, 109 (2014)

10. E. H. Livingston, J. Surg. Res., 119, 117 (2004)

11. Ø. Hammer, A.T. Harper, Palaeontol. Electron., 4, 4 (2001)

12. PAST - PAleontological Statistics, Version 4.03. Reference manual (Natural History Museum, 2020) 